\title{
Couple-Friendly Services in a Metropolitan Sexually Transmitted Disease Clinic: Views of Clients and Providers
}

\author{
By Ross Danielson, Anita Barbey, Donna Cassidy, Julie Rosenzweig and Durre Chowdhury
}

Context: Clients making clinic visits related to reproductive health might benefit from participation with their partner. There is little information available, however, on whether either clients themselves or clinic staff would feel comfortable with such a possibility.

Methods: The Multnomah County Health Department Sexually Transmitted Disease Clinic in Portland, Oregon, conducted a survey of 237 new clients in June 1994 to assess clients' and providers' responses to the idea of offering couple visits.

Results: Twenty-six percent of female clients and $16 \%$ of male clients were accompanied by their partner on their visit to the clinic. Eighty-seven percent of all clients favored the clinic's offering couple visits, $5 \%$ opposed the concept and $8 \%$ were undecided. Fifty-four percent would have wanted their partner to be with them during their present visit if this choice had been offered, and $62 \%$ would want their partner to join them in follow-up couple visits if this were recommended by their provider. Seventy-one percent had already discussed with their partner the reason for their immediate clinic visit, and $88 \%$ expected to discuss the visit with their partner afterward. Attitudes toward couple services were similar for male and female clients and did not vary by race or ethnicity. For more than one-fifth of clients, clinic staff reported that they would not recommend couple visits; however, many of these clients reported that they would prefer being accompanied by their partner.

Conclusions: Appropriately designed couple-friendly options are likely to be generally accepted and moderately utilized by clients of varying backgrounds. Clinic staff may be more reluctant to involve clients' partners than the clients are themselves, however.

Family Planning Perspectives, 1999, 31(4):195-199

I n February 1994, the staff of the Multnomah County Health Department Sexually Transmitted Disease (STD) Clinic in Portland, Oregon, began discussions of couple-focused care* and how this concept might be put into practice in an STD clinic. The overall concept is to consider partners, couples and relationships more centrally in reproductive health. ${ }^{1}$ The clinic was especially interested in responding appropriately to clients who wanted to include partners in STD-related visits. A receptionist estimated that the clinic received one or two such requests daily, but clinic policy did not allow joint couple visits.

On considering the issue of partner involvement, a number of questions arose.

\footnotetext{
*We subsequently adopted the term couple-friendly care, which we found more useful and acceptable to the clinic staff.
}

How involved were partners already? How would clients feel about having the option to directly involve their partner in services? Would providers consider partner involvement inappropriate for some clients?

We found little in the professional literature to answer these questions, despite evidence and expert opinion that partner involvement may have value in reproductive health promotion, especially in family planning. A 1982 Canadian nursing discussion of "couple-directed contraceptive counseling" 2 argued that including both partners in services might promote an ideal of "mutually active compliance." And a nursing researcher who examined "contraceptive context" and "shared contraception" among couples practicing contraception in Northern California recommended "that a client be accompanied to the health care service by a significant other, such as a family mem- ber, or a partner or friend, who is willing to become a well-informed resource and support." ${ }^{3}$ This perspective on contraceptive context was offered as a model for increasing nursing involvement in family health.

Studies of the involvement of male partners appear to be more common in the international research literature. An influential 1963 Taiwan study found that including husbands in home visits that were focused on contraceptive education did not appear to be worth the extra effort. ${ }^{4}$ In contrast, a 1959 study of family planning in Puerto Rico argued "that a combination of clinical methods and husband orientation (that is, joint responsibility) would provide a more effective pattern of birth control use. ${ }^{\prime \prime}$ And a study of four comparison communities in Dhaka, Bangladesh, from 1961 to 1964 found that providing contraceptive education to both husbands and wives (albeit separately) was more effective than education directed to wives alone. ${ }^{6}$

These early examinations of partner involvement are complemented by more recent international studies. An Ethiopian study investigating home visits for con-

\footnotetext{
Ross Danielson is research director, Northeast Health Resource Center, Portland, OR. Anita Barbey is president, A.M. Barbey and Associates, Aurora, OR. Donna Cassidy is manager of the Multnomah County Health Department HIV Clinic, Portland, OR. Julie Rosenzweig is associate professor, School of Social Work, Portland State University, Portland, OR. Durre Chowdhury is associate professor in the Faculty of Medicine, Department of Community Medicine, Jordan University of Science and Technology, Irbid, Jordan. At the time that the research described in this article was conducted, Ross Danielson was adjunct associate professor and Durre Chowdhury was assistant professor, both in the Department of Public Health Education, Portland State University. The project described in this article was carried out by the staff of the Multnomah County Sexually Transmitted Disease Clinic, with the unreimbursed assistance of the authors. The authors gratefully acknowledge the resources contributed by their affiliated institutions, especially the Portland State University Faculty Resource Center. Stan Becker provided helpful comments on an early draft.
} 
traceptive education found that after one year, contraceptive prevalence was twice as high when services were provided jointly to husbands and wives as when the same services were provided to wives alone. ${ }^{7}$ In Madagascar, a test of husbands' involvement in contraceptive counseling, education and decision-making found beneficial effects for implant users. ${ }^{8} \mathrm{Fi}$ nally, a large randomized trial in China showed that providing contraceptive education jointly to couples resulted in fewer unwanted pregnancies and concomitantly fewer abortions than providing comparable education to individuals. ${ }^{9}$

It is plausible that a couple-directed intervention would be useful, given the accepted value of enhancing couple communication, ${ }^{10}$ increasing the normative and affective support of mutual agreement and reducing mutual misunderstandings. Household interviews with Florida couples found "enormous" misconceptions and misunderstandings between partners: Wives were more likely than husbands to misunderstand their spouse's contraceptive values, women underestimated their husband's willingness to use condoms, men overestimated their wife's valuation of condoms and wives were significantly more bothered than their husband was by the disadvantages of condoms. The report concluded that seeing both partners in family planning services would be much more beneficial than talking only to the woman. ${ }^{11}$

Surveys of men's attitudes find that men are generally more supportive of contraception than is conventionally believed, and that there is greater concurrence between the sexes or within couples than is generally thought. ${ }^{12}$ Many studies have examined partners' roles in contraception and fertility, ${ }^{13}$ but a full consideration of partners, men and both sexes in demographic theory and research has been problematic. ${ }^{14}$

The relationship context is increasingly viewed as important in interpreting data on condom use and STD prevention. ${ }^{15}$ Studies of HIV-discordant couples suggest that involving partners and providing counseling to both partners promotes improved condom use and safer sexual practices. ${ }^{16}$

A recent Ecuadoran survey of more than 3,000 female clients in 12 clinics found that the great majority favored pro-

\footnotetext{
*This question was worded: "Would it have been inappropriate for the patient to have been accompanied by a partner today (with the partner initially staying in the waiting area but willing to be seen)?"
}

moting more partner involvement in women's reproductive health visits. Eighteen percent of female clients attending personal health visits were accompanied by their partner, $88 \%$ were willing to ask their partner to join them for couple visits if this were recommended by their provider, and 96\% expected to discuss with their partner the findings of clinic visits. Of 505 women who had received health counseling in the clinic jointly with their partner, all but two answered that they liked having their partner present, while $94 \%$ of women who had received counseling without their partner responded that they would have liked to have him present for the visit. ${ }^{17}$

Similarly, in a 1993 U.S. study of primarily black and Puerto Rican couples in which at least one partner was in a homeless shelter or a program to treat chemical dependency, the great majority of men and women were willing to join their partner for couple visits if these were recommended by the partner's provider. ${ }^{18}$

In this article, we define couple-friendly care as services that are open, welcoming and supportive to couples or partners; attentive to the concerns of intimate relationships; capable of providing couple-focused or partner-focused services, resources or referrals; able to apply an understanding of couple relationships; and respectful of couples as representing important resources, opportunities and challenges for reproductive health.

Aiming to understand better the acceptability of couple-friendly innovations, we examine here clients' views relating to a hypothetical offer of joint couple visits at a metropolitan STD clinic.

\section{Methods}

All clients who came to the clinic for an initial visit for STD-related care and who had not visited the clinic in the previous three months were eligible to be included in the study. Eligible clients were identified by the receptionist; the provider explained the study's goals and invited clients to complete a brief one-page questionnaire at a convenient time before leaving the clinic.

Potential participants were told that the survey was voluntary and anonymous, and were asked to place their completed form in a sealed envelope and return it to their provider or to the receptionist. We further assured confidentiality by having the anonymous data processed offsite by investigators unaffiliated with the clinic. Providers were instructed to exclude clients from the survey whenever such participation seemed inappropriate or might interfere with care.

In addition, providers completed a onepage form for each eligible client. On it, they were asked to assess the appropriateness of partner involvement for each client. ${ }^{*}$ The form also included a checklist of possible services, and providers were asked to indicate which interventions they might have considered offering if that client's partner had been present and willing to be seen.

Study procedures were uniformly applied during four weeks of June 1994, to provide data on a complete series of qualifying clients who elected to participate. During that time, 281 clients were identified by the receptionist as potential study participants. Of these, 20 were excluded because they did not speak English, 10 were excluded because time constraints or circumstances of the visit made the survey too burdensome, two were excluded because of mental limitations and five because their visit was limited and brief; reasons for exclusion were not recorded in six cases. In addition, one client agreed to participate but chose to leave the questionnaire blank. In all, then, questionnaires for 237 clients were available for analysis. In addition, eight providers participated, each completing anywhere from 10 to 51 forms. A high item-completion rate suggests that clients had little difficulty understanding the questions.

Questionnaires were designed to be self-completed in 5-10 minutes, and cov- 
ered only those areas considered by the clinic staff and investigators to be specifically appropriate and relevant for the narrow planning purposes of the study. The clients' questionnaire explained that "We are thinking about offering a new service called 'couple-focussed care.' Under couple-focussed care, clients who have concerns about sexually transmitted disease would be invited to ask their partner to come with them to the clinic. All clients and partners would be examined individually and confidentially. If desired and appropriate, they would also be counseled together, with their partner, for any shared concern."

Data on the partner's sex were not collected, because we expected too few samesex relationships to permit separate analysis. In addition to the structured response categories, the questionnaire solicited written comments on key items. Pilot testing of the instrument was conducted with 18 clients; since the instrument and methods were modified only slightly as a result of the pilot data, these are included with subsequent responses in this analysis.

\section{Findings}

\section{Client Characteristics}

Forty-six percent of clients were female. Providers classified $63 \%$ of clients as white, $30 \%$ as black, 3\% as Hispanic and $4 \%$ as of other race or ethnicity. Eleven percent were younger than $18,18 \%$ were $18-20,41 \%$ were $21-30$ and the remaining $30 \%$ were older than 30 . Clients younger than 18 were more likely to be black and more likely to be female.

Twenty-two percent of clients were seeking routine screening; $19 \%$ had complaints or symptoms consistent with chlamydia, nongonococcal urethritis or pelvic inflammatory disease; $9 \%$ had probable herpes or condyloma; $24 \%$ had data consistent with other bacterial STDs, including gonorrhea; $4 \%$ were seen for yeast or for symptoms not related to STDs; $5 \%$ had miscellaneous complaints; and in the remainder of cases, the provider gave no information on the client's complaint or diagnosis. At least $13 \%$ of clients were worried that they had been exposed to a partner with disease, symptoms or concerns about disease. Some of these clients had been contacted by the health department's contact tracing.

\section{Providers' Views}

In about $18 \%$ of cases, the provider considered that it definitely would have been inappropriate to have involved the client's partner in that visit, and in another $7 \%$ be- lieved that it might have been inappropriate. The providers' reasons for making this judgment principally concerned the newness of a relationship or its casual, nonmonogamous or unstable character. In at least three cases, the provider was concerned with potential anger and its consequences: One patient was openly angry at her partner, a second was afraid that her partner would be angry at her infidelity, and a third had a history of domestic violence. Sometimes providers considered partner involvement inappropriate because the partner had already been seen for the shared health concern. The providers' judgments did not appear to be associated with their clients' ethnicity, gender or age.

Providers assessed what services would be appropriate for a client in $79 \%$ of the cases (a total of 186 clients). In the providers' views, the primary benefits to having the partner accompany the client were the opportunity to provide complementary education, counseling, examination and treatment (Table 1). In $57 \%$ of cases, the provider would have offered couple counseling, in 10\% the provider suggested return referrals for couple visits and in $9 \%$ the provider would have referred the couple elsewhere for services.

Providers' considerations of hypothetical services to partners were not associated with the clients' gender or ethnicity. However, providers were more likely to want to have partners of older clients than partners of younger clients examined $(\mathrm{R}=.15, \mathrm{p}<.05)$ or treated $(\mathrm{R}=.20, \mathrm{p}<.01)$. $^{*}$

\section{Clients' Views}

Eighty-seven percent of respondents supported the proposal to offer couple visits (Table 2). The high level of support leaves little opportunity to examine variation within categories of clients.

Clients' comments revealed their motives, and sometimes their enthusiasm, in support of couple visits. According to some clients, couple visits could help expand choices for clients, make care easier for both partners, increase couple communication on sexual health matters, improve relationships, increase the educational value of services, provide comfort and reassurance to clients, and increase partners' support for clients' adherence to treatment and prevention. Some con- sidered couple services especially valuable for new couples, while others thought that couple visits would be best for clients who had regular partners. No comments were offered by the few who opposed offering couple visits.

Twenty-one percent of clients were accompanied to the clinic by their partner (Table 3, page 198). There were no statistically significant differences by ethnicity, age and sex in the likelihood that a client had been accompanied by his or her partner.

We used two questions to assess clients' degree of interest in involving their partner in medical visits: one hypothetical question concerning the study visit ("Would you have wanted to bring a partner for today's visit, if this choice had been available?") and one concerning a followup visit ("Would you want a partner to come with you on your next visit, if your nurse suggested this?").

More than half of clients responded to each question affirmatively, about onefourth expressed uncertainty and fewer than one in five said no (Table 2). Differences in responses by sex, age or ethnicity were not statistically significant. Some clients commented that couple visits would help them disclose information to partners, such as having herpes; some wanted to involve former partners as well as present partners; and others simply felt that sharing visits made sense because they "shared everything else." A few clients expressed a desire to have a couple visit before having unprotected sex with a new partner. Those who responded that they would not want to include their partner mentioned scheduling problems and not having a partner who was appropriate for such participation.

The data also offer us an opportunity to

*Spearman's rank-order correlation was used to indicate the association between age-groups and hypothetical intervention assignment (yes, undetermined or no.) 
Table 3. Percentage of clients who were accompanied by a partner at the time of the visit, by client characteristics

\begin{tabular}{llr}
\hline Characteristic & $\%$ & $\mathrm{~N}$ \\
\hline All & $\mathbf{2 0 . 7}$ & $\mathbf{2 3 2}$ \\
Ethnicity & & \\
Black & 14.5 & 69 \\
White & 20.7 & 145 \\
Other & 43.8 & 16 \\
Age & & \\
$<18$ & 32.0 & 25 \\
$19-20$ & 22.5 & 40 \\
$21-30$ & 17.7 & 96 \\
$>30$ & 19.7 & 71 \\
Sex & & \\
Male & 16.1 & 124 \\
Female & 25.7 & 105 \\
\hline
\end{tabular}

consider how closely providers' perceptions of clients' "appropriateness" for partner involvement matched clients' opinions and preferences related to couple-oriented care. When we restricted this analysis to clients with current partners, there were no important differences in support for couple visits between clients judged "inappropriate" and others. Moreover, "inappropriate" clients were similar to others in their interest in including partners in couple visits.

Further examination suggests that clients' interest in their partner's involvement may be quite different from their provider's expectations. One woman who was a victim of domestic violence was accompanied by her partner and also wanted her partner to join her in a hypothetical follow-up visit. Another client who was afraid of her partner's anger over her infidelity nonetheless wanted to include her partner in a follow-up visit and planned to speak to him about the health concern that motivated her visit.

Forty-three percent of clients reported either that they had no knowledge of their partner's care or related plans, or that their partner had not sought care and did not plan to do so. Nevertheless, $71 \%$ reported having talked to their partner about their health concern before their visit. Moreover, $88 \%$ intended to talk to their partner about their health problem after the visit, while only $4 \%$ did not intend to do so and $8 \%$ were undecided. Small differences by gender, ethnicity and age were not statistically significant.

\section{Discussion}

The urgent need to improve the treatment and control of STDs and HIV and to promote reproductive health calls for innovative approaches to more optimally involve couples and partners, especially since research has demonstrated that improved partner involvement may lead to better outcomes. Such innovation can be stymied, however, when clinic staff are uncertain whether clients will support such an approach or anticipate conflicts with the privacy of the provider-client relationship and with other interests, including preventing partner violence.

Therefore, research into the actual interests and desires of clients and their current patterns of partner involvement is an important first step in preparing for partner-involving innovation. Our research, in demonstrating one approach to collecting such data, finds widespread client support for such couple visits, substantial interest in using them, considerable direct and indirect partner involvement already and no expressed concerns by clients about the potential for partner violence. These findings do not lessen the importance of protecting client privacy and autonomy or protecting against partner violence, but rather recast these goals within the challenge of designing innovations to enhance appropriate partner involvement.

We expect that appropriately designed and promoted couple visits would be widely accepted by clients and moderately used in the study setting. A substantial proportion of clients said they would have wanted to include their partner in the present visit, a somewhat larger proportion said they would want a partner to attend a follow-up visit if this were suggested by the provider, some one in five clients already attended the clinic with their partner, and a large proportion of clients either talked to their partner before their visit or planned to do so afterward.

As a first step toward couple-friendly innovation, ways might be considered to include partners who have accompanied the client to the provider in the educational part of a visit. The obvious enthusiasm of some clients for the offer of couple visits suggests that such an offer may increase client satisfaction and enhance the clinic's image. Also, given the limited amount of opposition to the offer and the absence of negative comments, the offer of couple visits would likely cause little client dissatisfaction.

That clients who were considered by providers to be possibly inappropriate for partner involvement had nearly the same interest in couple-oriented services as other clients may illustrate partners' importance for each other, even when partnerships are nonmonogamous, conflictfilled or newly formed. Indeed, there may be special and urgent reasons to obtain couple services in such relationships.

Our interpretation of the data does not mean that we believe providers' reservations about services to new or unstable partners are in error, since such relationships no doubt present special risks and concerns, especially for confidentiality. We suggest, however, that such reservations may be usefully applied in the design of appropriate, noncoercive offers of coupleoriented options in STD services-options that allow clients to exercise their own choices and judgments concerning partner involvement. Given the diversity of client interests, one may wonder if some clinics' current policies of forbidding couple visits (justified as protective for clients) may sometimes cause harm.

Clients' comments about the applicability of couple-focused care for new or unstable couples and clients were mixed. Some believed that couple visits would be especially good for new couples, while others felt quite the opposite. This finding suggests that providers should accept ambiguity and leave it to clients to resolve it for themselves; clients who wish to make a couple visit early in a relationship may be prepared to accept the risks that this might entail. Providers may explain these risks to clients, but we suggest that such risks be weighed against the plausible preventive value of reaching newer and younger clients. ${ }^{19}$

Clients' opinions on the offer of couple visits ranged from policy-level considerations to highly personal interests. On a policy level, some clients viewed couple visits as an important option that would enhance client choice. Some expressed a belief in the rightness or justice of couple visits for partners who share sexual and other intimacy. On a personal interest level, clients noted the convenience and efficiency of serving two people in one visit, sharing information in an area known for insufficient communication and avoiding later misunderstanding with their partner. Some considered the visit an opportunity to save time in partner treatment and as a timely means to reach a partner who may have been a source of infection.

Some clients believed that visits would be more comfortable, less traumatic and less fearful if clients enjoyed the support (or "comfort zone") of an accompanying partner. As one client commented, "I am so terrified through these visits I would prefer to see a familiar face." Thus, couple visits may make care not only more accessible and timely for partners, but also more accessible for clients themselves, by reducing fears of medical visits. 
While some thought that the option of couple visits might reduce the pressure on "individuals," one client was emboldened to ask if it would be okay to bring a friend. The expression of such an interest is a reminder that personal barriers exist for many clients in seeking health care, and that such barriers are set partly by the degree to which health services expect or appear to require an extreme standard of individual autonomy and competence in the performance of the role of client and patient.

In this "formative" stage of research on couple-oriented care, the clients' comments offer important insights and hypotheses on possible benefits and issues for clients. Since opposition to partner visits was rare, however, this study was too small to capture data on reasons for such opposition. (An Ecuadoran study identified several reasons for opposition, including practical difficulties of partner attendance and modesty concerns of female clients. ${ }^{20}$ )

While the findings clearly encourage couple-friendly innovations in the Oregon setting, we recommend that other settings cautiously interpret findings that have not been widely replicated. Secondly, we recommend that providers interested in expanding partner involvement embark on planned innovation that gives adequate attention and resources to the inventive design of couple-friendly measures-approaches that are informed but not constrained by research perspectives and research support. Indeed, private and public support are needed for such planned innovation, but are now lacking. Successful innovation will naturally offer conventional opportunities for research and demonstration to test specific approaches. But special support for innovation is needed to adequately nourish the beginnings of partner-friendly work in environments dominated by service and program paradigms that focus first on individuals, second on families but rarely on couples.

\section{References}

1. Danielson R, Couple-focussed care in reproductive health: a concept paper, Occasional Paper, Portland, OR Community Health Consultants, 1992; and Danielson R and Parker-Cullen M, Couple-focussed care in reproductive health, paper presented at the annual meeting of the American Public Health Association, San Francisco, Oct. 24-28, 1993.

2. Redmond MA, Couple-directed contraceptive counseling, The Canadian Nurse, 1982, 78(8):38-39.

3. Swanson JM, The male role in family planning: the in- tegration of work, biographies, and the contraceptive regimen, some strategies and consequences, unpublished manuscript, University of California, San Francisco, 1980 (portions presented at the Eighth Annual Workshop on Psychosocial Factors in Population Research, Denver, Apr. 8, 1980); Swanson JM and Corbin J, The contraceptive context: a model for increasing nursing's involvement in family health, Maternal/Child Nursing Journal, 1983, 12(3):169-183; and Swanson JM, Shared contraception, in: Swanson JM and Forrest K, eds., Male Reproductive Health, New York: Springer, 1984, pp. 226-244.

4. Freedman R and Takeshita JY, Family Planning in Taiwan: An Experiment in Social Change, Princeton, NJ: Princeton University Press, 1969.

5. Hill R, Stycos JM and Back KW, The Family and Population Control: A Puerto Rican Experiment in Social Change, Chapel Hill, NC: University of North Carolina Press, 1959, p. 363 .

6. Green LW et al., The Dacca Family Planning Experiment: A Comparative Evaluation of Programs Directed at Males and at Females, Pacific Health Education Reports, No. 3, Berkeley, CA: University of California Press, 1972.

7. Terefe A and Larson CP, Modern contraception use in Ethiopia: does involving husbands make a difference? American Journal of Public Health, 1993, 83(11):1567-1571.

8. Sambatra F et al., The Effects of Husband's Involvement in the Pre-Introduction Trial of NORPLANT in Madagascar: Final Report, FISA Contract No. C190.23.A, 1 April 199031 December 1992, Population Council, New York, undated.

9. Wang CC et al., Reducing pregnancy and induced abortion rates in China: family planning with husband participation, American Journal of Public Health, 1998, 88(4):646-648.

10. Bean FD et al., Husband-wife contraception, wife's employment, and the decision for male or female sterilization, Journal of Marriage and the Family, 1983, 45: 395-403; Hill R, Stycos JM and Back KW, 1959, op. cit. (see reference 5); Polit-O'Hara D and Kahn JR, Communication and contraceptive practices in adolescent couples, Adolescence, 1985, 20(77):33-43; and Stycos JM, Back KW and Hill R, Problems of communication between husband and wife on matters relating to birth control, Human Relations, 1956, 9:207-215.

11. Severy LJ and Silver SE, Two reasonable people: joint decisionmaking in contraceptive choice and use, in: Severy LJ, ed., Advances in Population: Psychosocial Perspectives, Volume 1, London and Bristol, PA: Jessica Kingsley, 1993, pp. 207-227.

12. Ezeh AC, Seroussi M and Raggers H, Men's fertility, contraceptive use, and reproductive preferences, $\mathrm{De}$ mographic and Health Surveys Comparative Studies, Calverton, MD: Macro International, 1995, No. 18; Asociación Pro-Bienestar de la Familia Colombiana (PROFAMILIA), Conocimientos, Actitudes, y Comportamiento Sexual de los Adolescentes, 1993-1994: Compilación de Resultados, Bogotá: PROFAMILIA, 1995

13. Andres D et al, Couples' use of contraceptives: who decides and why, Research Bulletins, 2(5), 1983-1984 (Carolina Population Center, University of North Carolina, Chapel Hill); Beckman LJ, Husbands' and wives' relative influence on fertility decisions and outcomes, Population and Environment, 1984, 7:182-197; Boria-Berna M, Husband's role in birth control acceptance, Medical Aspects of Human Sexuality, 1972, 6:70-74; Chowdhury D, Determinants of contraceptive behavior among urban women of Bangladesh, unpublished PhD. thesis, University of Oregon Department of Community Health, Eugene, OR, 1992; Joesoef MR, Baughman AL and Utomo B, Husband's approval of contraceptive use in metropolitan Indonesia: program implications, Studies in Family Planning, 1988, 19(3):162-168; Nathanson CA and Becker $\mathrm{MH}$, Family and peer influence on obtaining a method of contraception, Journal of Marriage and the Family, 1986, 48(3):513-525; Severy LJ and Silver SE, 1993, op. cit. (see reference 11); Thompson L and Spanier GB, Influence of parents, peers, and partners on the contraceptive use of college men and women, Journal of Marriage and the Family, 1978, 39:481; and Zotti ME and Siegel E, Preventing unplanned pregnancies among married couples: are services for only the wife sufficient? Research in Nursing and Health, 18(2):133-142, 1995.

14. Becker $S$, Couples and reproductive health: a review of couple studies, Studies in Family Planning, 1996, 27(6):291-306; and Greene ME and Biddlecom A, Absent and problematic men: demographic accounts of male reproductive roles, Policy Research Division Working Paper New York: Population Council, 1997, No. 103.

15. Ku L, Sonenstein FL and Pleck JH, The dynamics of young men's condom use during and across relationships, Family Planning Perspectives, 1994, 26(6):246-251; and Pleck JH, Sonenstein FL and Ku LC, Changes in adolescent males' use of and attitudes toward condoms, 1988-1991, Family Planning Perspectives, 1993, 25(1):11-29.

16. Allen $S$ et al, Effect of serotesting with counselling on condom use and seroconversion among HIV-discordant couples in Africa, British Medical Journal, 1992, 304(6842):1605-1609; Costigliola P, Ricchi E and Chiodo F, Modifications of sexual behavior after counseling in stable heterosexual partners of HIV + VE subjects, International Conference on AIDS, 8(3):160 (abstract no. PUC 8045), July 19-24, 1992; Deschamps MM et al., Heterosexual activity in at-risk couples for HIV infection, International Conference on AIDS, 7(2):318 (abstract no. W.C.3089), June 16-21, 1991; Feldblum P et al, Efficacy of spermicide use and condom use by HIV-discordant couples in Zambia, International Conference on AIDS, (abstract no. WeC 1085), Amsterdam, July 19-24, 1992; Kakooza A, Attitudes of young people to counseling services and HIV screening and testing, International Conference on AIDS, 8(2):D441 (abstract no. PoD 53251), July 19-24, 1992; M'Pele P et al, Screening for HIV-1 infection in Africa: a problem within a problem, International Conference on AIDS, 7(1):428 (abstract no. M.D.4154), June 16-21, 1991; Padian NS et al., Prevention of heterosexual transmission of human immunodeficiency virus through couple counseling, Journal of Acquired Immune Deficiency Syndromes, 1993, 6(9):1043-1048; and Ragni MV and Nimarwicz P, Human immunodeficiency virus transmission and hemophilia, Archives of Internal Medicine, 1989, 149(6):1379-1380.

17. Vargas $\mathrm{T}$ et al, La participación de la pareja y del hombre en la salud reproductiva: perspectivas de usuarios y proveedores de servicios de CEMOPLAF, informe general, Quito, Ecuador: Centro Médico de Orientación y Planificación Familiar, 1998

18. Armstrong $\mathrm{K}$ and Bressler J, Family Planning Council of Southeastern Pennsylvania, Philadelphia, personal communication (in reference to project \#U62/ CCU307014-02), 1995.

19. Costigliola P, Ricchi E and Chiodo F, 1992, op. cit. (see reference 16 )

20. Vargas T et al., 1998, op. cit. (see reference 17). 